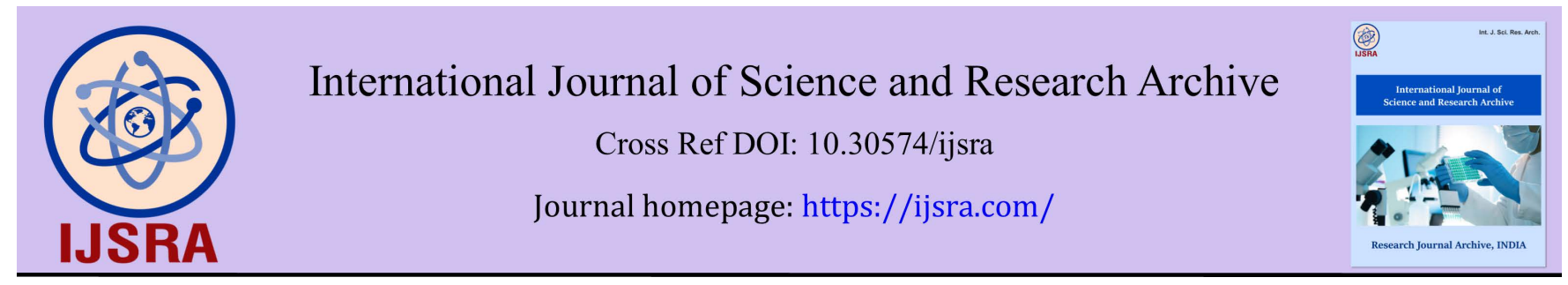

(RESEARCH ARTicle)

\title{
Stroke about very elderly patients in West African Country (Niger): Prognosis risk factors
}

\author{
Andia Abdoulkader ${ }^{1,}{ }^{*}$, Garba Abdoul Aziz ${ }^{3}$, Idrissa Hama ${ }^{2}$, Larent Youmbi ${ }^{1}$ and Brah Souleymane 1 \\ ${ }^{1}$ Internal medicine and geriatric department in Niamey's Reference hospital, $B P=12674$. \\ ${ }^{2}$ Cardiology department of Niamey's National hospital; $B P=238$. \\ ${ }^{3}$ General medicine department of Zinder's National hospital (Niger); $B P=155$.
}

International Journal of Science and Research Archive, 2021, 02(01), 006-011

Publication history: Received on 02 January 2021; revised on 10 January 2021; accepted on 12 January 2021

Article DOI: https://doi.org/10.30574/ijsra.2021.2.1.0001

\begin{abstract}
Background: Chronic diseases such as stroke most frequently occur on old people while literature on prognosis risk factors on elderly is rare particularly Sub-Sahara Africa. The aim of the study is to determine prognosis risk factors of stroke on elderly patients.
\end{abstract}

Method: It was a prospective cohort study carried out during 6 months that included elderly patients over 70 years old admitted in two tertiary medical emergency departments.

Results: 56 patients with mean age $75.2 \pm 5.17$ showed moderate NIHSS score $(59 \%)$ without gender predominance. $75 \%$ of patients with a severe score were in the 70-79 years old group. Functional dependency (93\%) increased with the NIHSS score severity and $50 \%$ of patients with a moderate NIHSS score showed normal nutritional status unlike patients with a severe NIHSS score and depression for most of the cases. Mortality was frequent for patients with hemorrhagic stroke with swallowing disorder and a severe NIHSS score.

Conclusion: Stroke on very elderly patients appears moderate with mortality chances increasing according to the severity of the NIHSS score, swallowing disorders that require a multidisciplinary approach in a neurovascular unit.

Keywords: Stroke; Elderly; NIHSS; Prognosis; Niger

\section{Introduction}

Global demographic aging will become the major challenge of the 21st century. Actually, it is already a reality in most of the health system of developed countries with the predominance of chronic diseases such as Strokes on elderly people. At the international level, data from the Global Burden of Disease showed that in developed countries there has been a $25 \%$ increase of yearly cases of stoke between 1990 to 2010 (from 4.2 to 5.3 million of cases) [1].

Stroke is a common condition in elderly people due to the increase in life expectancy and the associated vascular risk. At the same time, mortality has dropped in developed countries thanks to the neurovascular unit instead of high cost and motor sequelae. Stroke is the second leading cause of death in developing countries, behind cardiovascular disease [1]. In West Africa, the hospital frequency about stroke in young seniors was 18\% in Niamey, 30\% in Dakar, $29 \%$ in Ouagadougou and $28.5 \%$ in Gabon $[2,3,4,5]$. Literature about very elderly stroke is not frequent in sub-Saharan Africa while there is even the problem of early management in a neurovascular unit which undoubtedly improves the

\footnotetext{
${ }^{*}$ Corresponding author: Andia Abdoul Kader

internal medicine and geriatric department.

Copyright (C) 2021 Author(s) retain the copyright of this article. This article is published under the terms of the Creative Commons Attribution Liscense 4.0.
} 
prognosis at all ages. Our aim was to determine, through geriatric assessment, the prognosis factors that may interfere with the severity and mortality of stroke in the elderly aged over 70 years in Niger.

\section{Methodology}

It was a prospective multicentric and descriptive continuous study lasting 6 months (June 2018 to November 2018) in the medical emergency services of the National Hospital of Niamey (HNN) and the General Reference Hospital (HGR) of Niamey. The study involved patients with age 70 and over after receiving free and informed consent. The criteria for non-inclusion were: Patients who had a Transient Ischemic Attack (TIA), Patients without helpers and in coma, Patients with an incomplete records or patients refusing to participate in the study. When they returned home, the patients were called back to determine the evolution for those who did not return for follow-up consultations.

The data collection was done using the survey form on which was listed: the hospitalization registry and medical observation of patients. The variables studied were: Sociodemographic variables (age, sex, marital status, provenance, activities), co-morbidities, clinical and para clinical aspects, therapeutic, progressive and prognosis aspects. The patients and / or their entourage answers were definited: (good evolution = response without any complaint; Death = death of the patient; Lost $=$ absence of information in relation to his clinical state; Readmission = rehospitalisation in any health center for any reason; Loss of autonomy of basic life activities (scales of Katz and Lawton) = regression of autonomy compared to previous hospitalization; Stationary status = no clinical change compared).

The data were collected using a survey form using the National institute health severity score (NIHSS), mini nutrionnal assessment (MNA) scores and Globale disease scale for depression. Swallow disorders were screened by Smithard tools [6]. The analysis and data entry were carried out using Word software from the 2010 office pack, Epi info version 3.5 .1 and Excel from the 2010 office pack.

\section{Results}

Table 1 Distribution of patients among NIHSS score

\begin{tabular}{|l|l|l|}
\hline NIHSS score & $\begin{array}{l}\text { n } \\
\text { (Number) }\end{array}$ & Percentage \\
\hline Moderate stroke & 33 & 58.93 \\
\hline Severe stroke & 16 & 28.57 \\
\hline Worst stroke & 7 & 12.50 \\
\hline Total & 56 & 100.00 \\
\hline
\end{tabular}

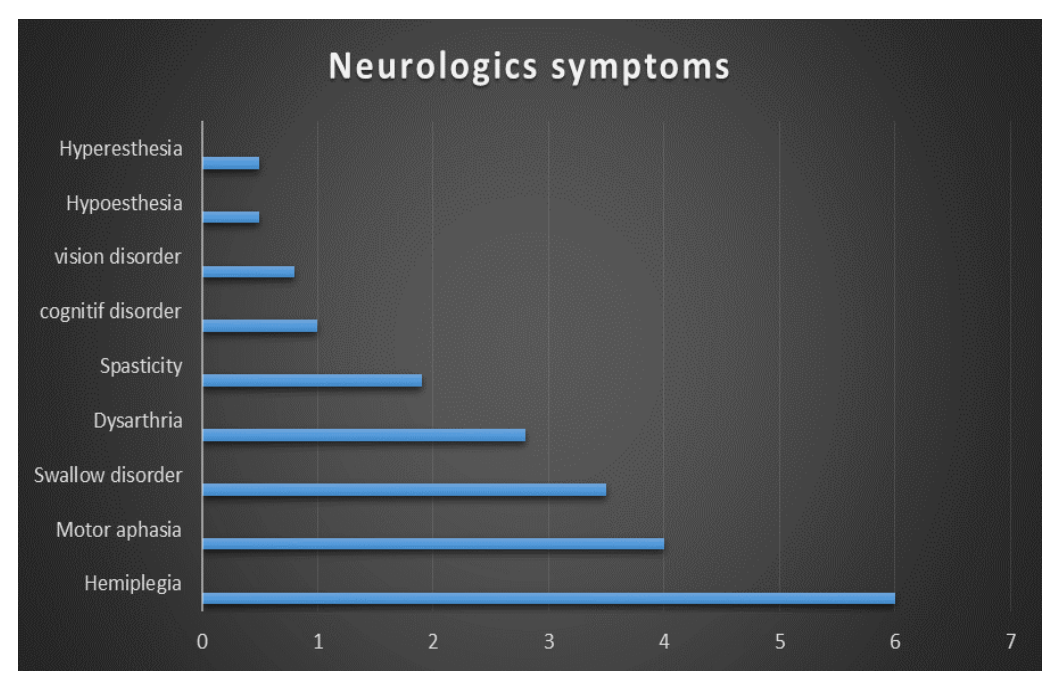

Figure 1 Neurologic manifestations 
Table 2 prognosis risk by score de NIHSS

\begin{tabular}{|c|c|c|c|c|c|}
\hline Score de NIHSS & Moderate stroke & Severe stroke & Worst stroke & Total & $P$ \\
\hline \multirow[t]{2}{*}{$\begin{array}{l}\text { Range years } \\
70-79 \text { years } \\
\geq 80 \text { years } \\
\end{array}$} & $\begin{array}{l}23 \\
10 \\
\end{array}$ & $\begin{array}{c}12 \\
4\end{array}$ & $\begin{array}{l}6 \\
1\end{array}$ & $\begin{array}{l}41 \\
15\end{array}$ & $p=0,7$ \\
\hline & 33 & 16 & 7 & 56 & \\
\hline \multirow[t]{2}{*}{$\begin{array}{l}\text { Sex } \\
\text { Women } \\
\text { Male } \\
\end{array}$} & $\begin{array}{l}15 \\
18\end{array}$ & $\begin{array}{l}9 \\
7\end{array}$ & $\begin{array}{l}3 \\
4\end{array}$ & $\begin{array}{l}27 \\
29\end{array}$ & $p=0,4$ \\
\hline & 33 & 16 & 7 & 56 & \\
\hline \multirow[t]{2}{*}{$\begin{array}{l}\text { Good evolution } \\
\text { Death } \\
\text { Stationnary } \\
\text { Lost } \\
\text { Recidive } \\
\end{array}$} & $\begin{array}{c}18 \\
4 \\
8 \\
2 \\
1 \\
\end{array}$ & $\begin{array}{l}5 \\
4 \\
6 \\
0 \\
1\end{array}$ & $\begin{array}{l}2 \\
5 \\
0 \\
0 \\
0\end{array}$ & $\begin{array}{c}25 \\
13 \\
14 \\
2 \\
2 \\
\end{array}$ & $p=0,04$ \\
\hline & 33 & 16 & 7 & 56 & \\
\hline \multirow[t]{2}{*}{$\begin{array}{l}\text { Nutritionnal status } \\
\text { Normal } \\
\text { Risk } \\
\text { Denutrition }\end{array}$} & $\begin{array}{c}13 \\
20 \\
0\end{array}$ & $\begin{array}{l}6 \\
9 \\
1\end{array}$ & $\begin{array}{l}1 \\
4 \\
2\end{array}$ & $\begin{array}{c}20 \\
33 \\
3 \\
\end{array}$ & $p=0,3$ \\
\hline & 33 & 16 & 7 & 56 & \\
\hline \multirow[t]{2}{*}{$\begin{array}{l}\text { Autonomy } \\
\text { Dependent } \\
\text { Partial } \\
\text { Non dependent } \\
\end{array}$} & $\begin{array}{l}4 \\
23 \\
6 \\
\end{array}$ & $\begin{array}{c}0 \\
11 \\
5 \\
\end{array}$ & $\begin{array}{l}0 \\
4 \\
3\end{array}$ & $\begin{array}{c}4 \\
35 \\
14\end{array}$ & $p=0,02$ \\
\hline & 33 & 16 & 7 & 56 & \\
\hline \multirow[t]{2}{*}{$\begin{array}{l}\text { Depression } \\
\text { Yes } \\
\text { No } \\
\end{array}$} & $\begin{array}{l}20 \\
13 \\
\end{array}$ & $\begin{array}{l}11 \\
5 \\
\end{array}$ & $\begin{array}{l}6 \\
1 \\
\end{array}$ & $\begin{array}{l}37 \\
19 \\
\end{array}$ & $p=0,4$ \\
\hline & 33 & 16 & 7 & 56 & \\
\hline
\end{tabular}

Table 3 Risk factor of mortality

\begin{tabular}{|c|c|c|c|c|}
\hline \multirow[b]{2}{*}{ Events } & \multicolumn{2}{|c|}{ Mortality } & & \multirow[b]{2}{*}{$\mathbf{P}$} \\
\hline & Yes & No & Total & \\
\hline \multicolumn{5}{|l|}{ Swallowing disorders } \\
\hline Present & 10 & 3 & 13 & $p=0,02$ \\
\hline \multirow[t]{2}{*}{ Non-present } & 23 & 30 & 43 & \\
\hline & 33 & 33 & 56 & \\
\hline \multicolumn{5}{|l|}{ Type of stroke } \\
\hline Infarcis stroke & 7 & 38 & 45 & $p=0,03$ \\
\hline \multirow[t]{2}{*}{ Hemmoragic stroke } & 6 & 5 & 11 & \\
\hline & 13 & 43 & 56 & \\
\hline
\end{tabular}


International Journal of Science and Research Archive, 2021, 02(01), 006-011

\begin{tabular}{|l|c|c|c|l|}
\hline $\begin{array}{c}\text { Depression } \\
\text { Yes }\end{array}$ & 8 & 29 & 37 & $p=0,7$ \\
No & 5 & 14 & 19 & \\
\hline & 13 & 43 & 56 & \\
\hline Nutritional status & & & & \\
Normal & 2 & 18 & 20 & $p=0,1$ \\
Risk of denutrition & 9 & 24 & 33 & \\
Denutrition & 2 & 1 & 3 & \\
\hline & 13 & 43 & 56 & \\
\hline
\end{tabular}

\section{Discussion}

In our study, the major NIHSS score was between $5-15$ and corresponding to a moderate stroke (58.9\%). Similar results were found in Rachid L study in Morocco (72\%), Anselm in Burkina and Bertha study 53,3\% about young elderly population in Nigeria. $[7,4,8]$ The African demography population is globally young and could explained the moderate gravity of NIHSS score. Among patients with severe stroke, the 70 to 79 age group was the most represented with $75 \%$ ( $\mathrm{p}=0.7$ ) with female majority in $56.2 \%(\mathrm{p}=0.4)$. In the study of Dauphin A., the age was not considered as an unfavorable risk factor contrary in Davis and coll. study and the series of Calmel P. and coll. concerning elderly subjects at beyond 80 years. $[9,10,11]$ Then, we didn't find data about stroke in oldest elderly patient over or equal to 70 years old in sub-Saharan Africa. The epidemiology of stroke in Europe reports a 100-fold increase in subjects over the age of 80 regardless of gender [12]. Regarding the geriatric evaluation in our study, patients who presented with a severe or worst stroke were totally functional dependent $(8 / 23)$ compared to those with a moderate stroke. $(p=0,02)$. The study of Dauphin and coll. supports the severity of stroke in the functional prognosis of elderly like in Davis JP and coll. study (aged over 80 years old) in which the functional prognosis depended to motor impairment $[9,10]$. Indeed, the disability in daily life activities were important by motor functions deficient which were mainly reached $(90 \%)$ in our study. The other prognosis NIHSS risk factors were nutritional status in which more than $50 \%$ with moderate strokes had a normal nutritional status compared to severe and worst strokes ( $\mathrm{P}=0.7)$; in the Davis JP and coll. al study the functional and vital prognosis depended to denutrition [10]. It was in our study about sub-acute phases but the impact of denutrition could be seen in the long term. Also, almost all of the patients with severe stroke were depressed ( $p=0.4)$. In Davis JP and coll. study there was residual depressive syndrome in 21\% [10]. Depression affects 20 to $30 \%$ of stroke patients and this risk increases with age which can worsen motor and cognitive disabilities [13]. The overall mortality in our series was 23\% which is less than in Berthe E study (35\%) in young adult's patients but our result was higher than in Anslem A study's from Burkina Faso (12,5\%) about young elderly patients as in the Dijon's series (21\%) in elderly over 80 years old at 28 days. $[8,4,14]$. This difference was due to the sampling as well as to the heterogeneity of the inclusion age criteria. In Berth E study the important predictors of mortality were the presence of comorbid conditions $(\mathrm{p}=0,02)$, NHISS score $(\geq 16)$. [8] In our study, mortality was higher in patients with a high NIHSS score $(71.4 \%)(p=0.04)$. The NIHSS score constitute is a prognosis risk factor for stroke in elderly. This association was reported by Europe serie's Sautereau $[15,10]$. In our study, patients with a swallowing disorder had higher mortality $(77 \%)(p=0.02)$. Indeed, the occurrence of swallowing disorders during stroke in the elderly, increases the risk of developing other complications such as pneumonia, denutrition;

Sautereau A in France also found in his study a statistically significant relationship between swallowing disorder and the mortality of elderly patients with stroke $(\mathrm{p}<0.001)$ [15]. In the adult population, Jeoffray Diendéré in Burkina Faso also found $37 \%$ of mortality in patients with swallowing disorder against $6 \%$ in patients without swallowing disorder. Hemorrhagic stroke in our series, was a risk factor for mortality $(p=0.03)$, unlike the series of Anselm A ( $p=0.29)$ in young elderly patients $[6,4]$. We did not find a statistically significant relationship with denutrition and depression on the mortality. In the study of Davis JP and Coll, the vital prognosis depended to denutrition, size of infarcis or hemorragic stroke and the quality of initial management [10]. Our context is characterized by a delay in treatment as well as difficult access in terms of cost of neuro imageric stands which makes the establishment of a neurovascular unit difficult in despite the existence of a multidisciplinary team

\section{Conclusion}

The vital prognosis risk factors in oldest elderly stroke's in Niger were: presence of swallowing disorders, hemorrhagic stroke and severity of NIHSS score which specially impacted in functional prognosis. 


\section{Compliance with ethical standards}

\section{Acknowledgments}

The authors wish to acknowledge with gratitude the authors whose works were extensively used in this study and duly acknowledge in the reference section.

\section{Disclosure of conflict of interest}

The authors hereby attest to the fact that there is no any conflicting interest of any sort in this study.

\section{Statement of informed consent}

Informed consent was obtained from all individual participants included in the study.

\section{References}

[1] Lopez AD, Mathers CD, Ezzati M, Jamison DT, Murray CJ. Global and regional burden of disease and risk factors, 2001 : systematic analysis of population health data. Lancet. 2006; $367: 1747-57$.

[2] Andia A, Brah S, Daou M, Zara M, Beydou S, Aminou MS and coll. Geriatric in Patient Profile at the Department of Internal Medicine at Niamey National Hospital, Niger. European Scientific Journal September edition. $2017 ; 13$.

[3] Touré K, Ndiaye NM, Diouf F, Sène F, Ndiaye M, Diallo K et al. Evaluation du coût de prise en charge des accidents vasculaires cérébraux à Dakar Sénégal. Med Trop. 2005; 65: 458-64.

[4] Anselme DA, Adeline Keylem JM, Dravé A, Tanguy Nikièma MI, Napon C, Kaboré J. Les accidents vasculaires cérébraux chez le sujet âgé en milieu tropical : aspects épidémiologiques, cliniques et facteurs pronostiques. Neurol psychiatr gériatr. 2018.

[5] Kouna Ndouongo P, Millogo A, Siéméfo Kamgang FP, Assengone ZY. Aspects épidémiologiques et évolutifs des accidents vasculaires au centre hospitalier de Libreville (Gabon). AJNS. 2007; 26(2): 12-7.

[6] Jeoffray DIENDERE . Evolution de l'état nutritionnel et des troubles de la déglutition au cours des accidents vasculaires cérébraux, en milieu hospitalier au Burkina Faso, thèse de de doctorat. 2017; 104.

[7] Rachid L Pronostic des accidents vasculaires cérébraux ischémiques. Etude prospective sur 7mois. Mémoire de médecine. Fès. 2013; 24.

[8] Berthe E., Adelosa O.,Emmanuel I., Udeme E. Stroke mortality and its predictors in a Nigeria teaching hospital. African Heath Sciences. March 2015; 15(1). Dauphin A, Thevenon A. Critères de choix des filières de soins dans la rééducation de l'hémiplégie vasculaire. Ann Readap Med Phy. 1997; 40: 255-64.

[9] Davis JP, Wong AA, Schluter PJ, Henderson RD, O’Sullivan JD, Read SJ. Impact of premorbid undernutrition on outcome in stroke patients. Stroke. 2004; 35: 1930-4.

[10] Calmels P, Defay C, Yvanes-Thomas M, Sylvie L , Isabelle FM et al. L'âge très élevé constitue-t-il un facteur pronostique du devenir après un premier accident vasculaire cérébral ? Ann Readap Med Phy. 2005; 48: 675-81.

[11] Bejot Y, Bailly H, Durier J, Giroud M. Epidemiology of Stroke in Europe and trends for the 21 st century. Presse Med 2016; 45: e391-e398.

[12] Pinoit JM, Bejot Y, Rouaud O, Benatru I, Osseby GV, Bonin B, isépiet al. Dépression après un accident vasculaire cérébral, un handicap supplémentaire. Presse Med 2006; 35 : 1789-93.

[13] Bejot. Y, Rouaud O, Gentil A, M. Caillier , Manckoundia P , Osseby GV, T et al. Les accidents vasculaires cérébraux du sujet âgé : ce que nous a appris l'épidémiologie du sujet jeune. Revue neurologique. 2008; 164: 809-814.

[14] Sauterau A. Accident vasculaire cérébral de la personne âgée particularités et facteurs pronostiques. Thèse de médecine. Paris. 2009; 171. 